\title{
Incidence and risk factors of PONV in ENT surgery
}

Marcotegui Caminero J., Espinosa Organista A., Casares Acuña S., Martins Cruz K., Represa Sánchez M., Spinoni A. Clínico San Carlos Hospital, Dept of Anaesthesiology, Reanimation \& Pain Medicine, Madrid, Spain.

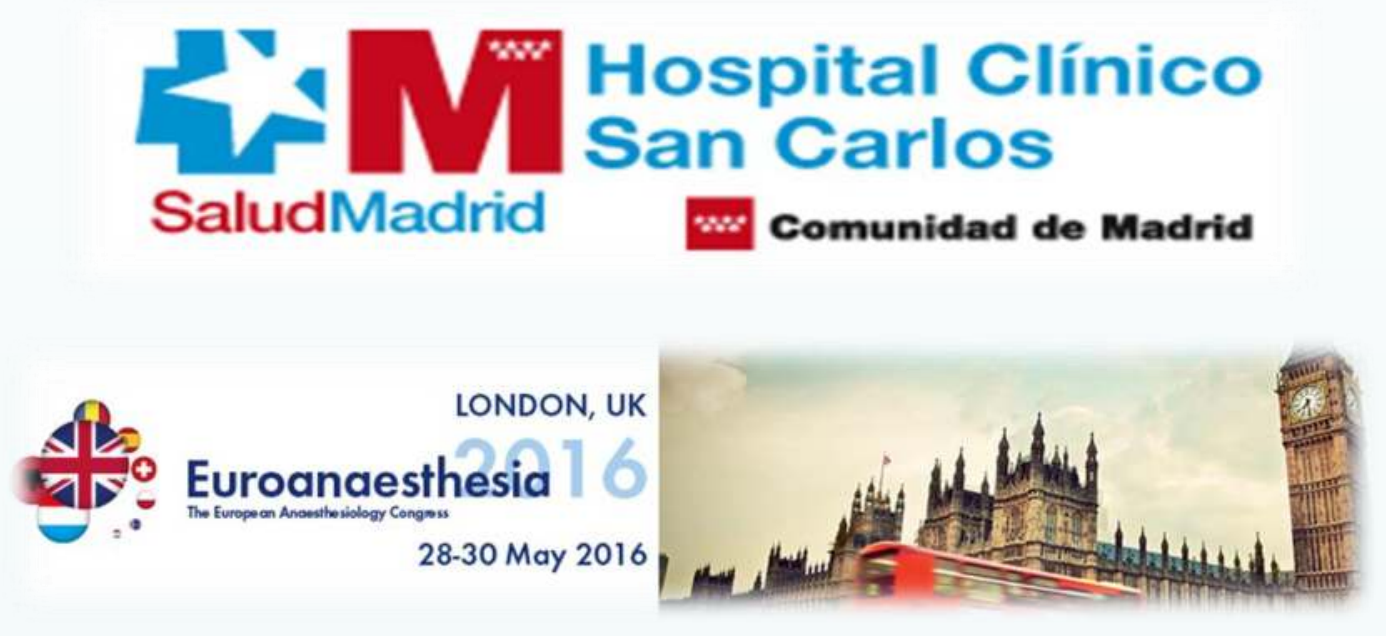

Introduction: Postoperative nausea and vomiting (PONV) is a common adverse event that generates additional problems to the patient and increases hospital costs. Their frequency varies widely according to the literature, being even higher in earnose-throat (ENT) surgery. There are some predictors of risk that determine the need of prophylactic drugs. We started this study to know the extent of the problem in our environment, in order to improve patient's safety and comfort.

Methods: Observational descriptive study (noninterventional) of 128 patients undergoing ENT surgery in Clínico San Carlos Hospital, Madrid. We calculated the desired sample size using an average incidence extracted from the literature. Routine clinical practice of the center was followed and all relevant data were collected: gender, smoking, previous PONV, ASA, length and type of surgery, use and dosage of propofol, opioids, corticosteroids, ondansetron, metoclopramide, atropine, sugammadex, positive facial-mask pressure ventilation, gastric suction, hemodynamic events, vasopressors, and fluids used. Data were collected at the operating room, post-anesthesia recuperation unit, and hospital room / patient's home (telephonically). We considered PONV as any patient's nausea sensation which required professional's help, or any active vomit in the first 24 hours after anesthesia. Center's Ethics Committee approved the study and each patient received an informed consent.

Objective: To measure the incidence of PONV with TIVA and dexamethasone used as prophylaxis, and seek relationship with yet known risk factors (demographic, surgery-related, and anesthesiarelated).

1. Jochen P. Windfuhr, Yue-Shih Chen, Evan J. Propst, Christian Güldner. The effect of dexamethasone on post-tonsillectomy nausea, vomiting and bleeding Braz J Otorhinolaryngol.2011;77(3):373-9.

Francisco Acosta-Villegasa,b,, Jose Antonio Garcla-Lopeza,by Jose Luis Aguayo-Albasin Manejo de las náuseas y vómitos postoperatorios Cirugia Española 2010;88(6):369-373.

3. Tong J. Gan, MD, MHS, FRCA, Pierre Diemunsch, MD, PhD, Ashraf S. Habib, MB, FRCA et al. Consensus Guidelines for the Management of Postoperative Nausea and Vomiting Society for Ambulatory Anesthesiology January 2014 • Volume 118 • Number 1.

4. J. I. Gómez-Arnau, J. L. Aguilar, P. Bovaira, et al. Recomendaciones de prevención y tratamiento de las náus. A y vómitos postoperatorios y/0 asociados a las infusiones de

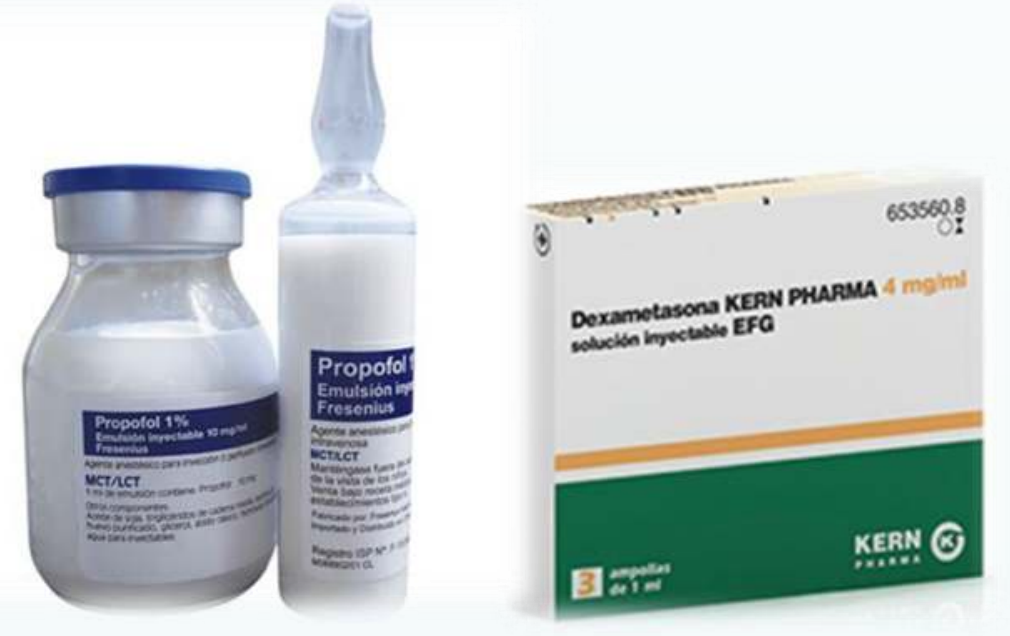

Results: PONV incidence of $\mathbf{3 . 1 \%}$ was obtained, and also a statistically significant relationship with induction dose of propofol (protective factor, $p=$ 0.021 ), total dose of propofol used (protective, $p=$ 0.04 ) and dexamethasone dose (protective, $p=$ 0.03 ). The relationship with the classical risk factors (patient-related, surgery-related, other drugs, and hemodynamic) was not significant.

Discussion: The low incidence of PONV prevented us to obtain statistically significant association with many of the studied variables; their confidence intervals were on the borderline. Therefore a larger sample would be necessary, because the sample size was originally calculated in relation to a bigger incidence obtained from the literature review.

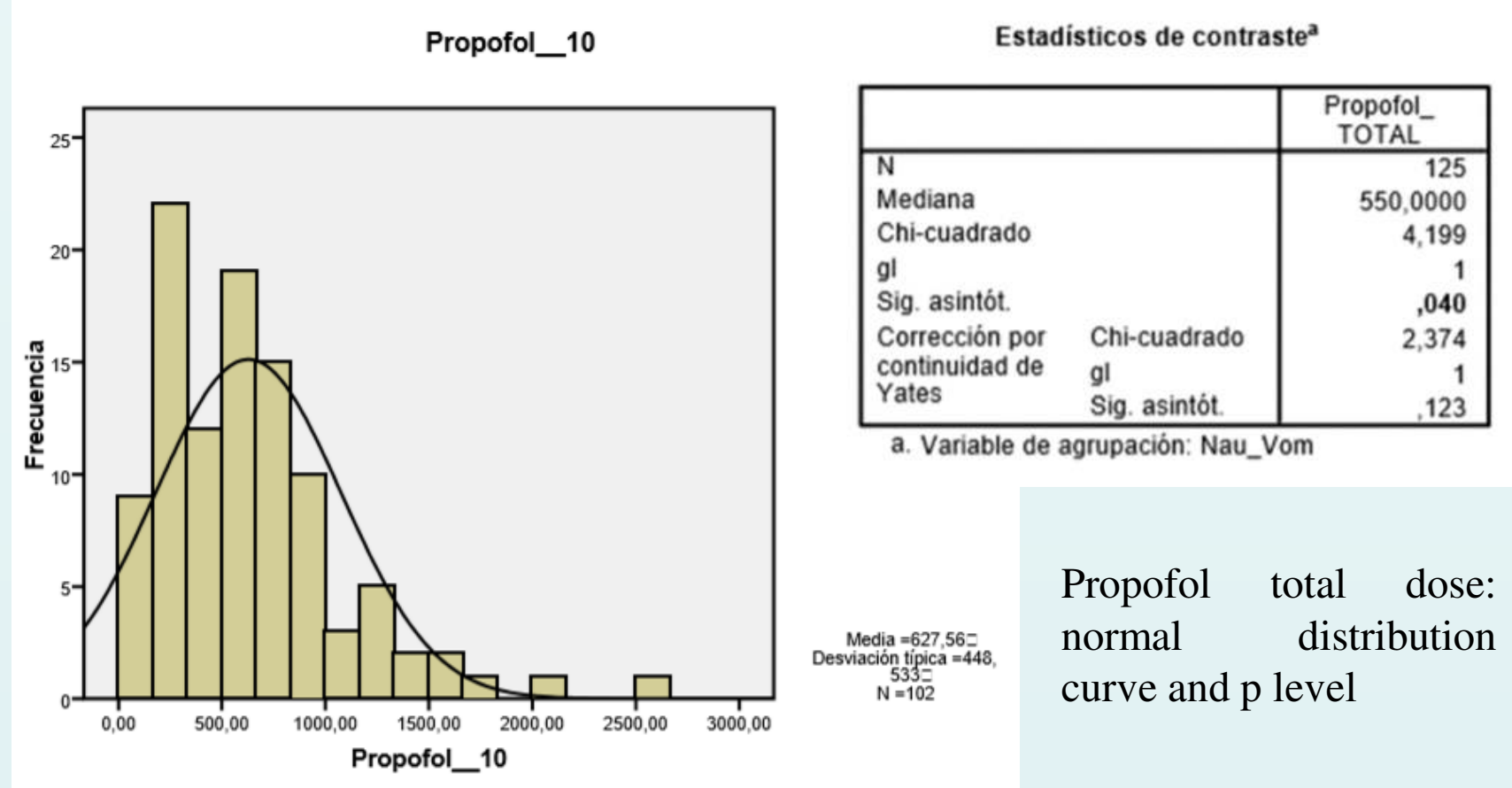

\section{Conclusions:}

1. The observed incidence of PONV is much lower than the one described in the literature.

2. Prophylaxis with dexamethasone and TIVA is effective in reducing the incidence of PONV.

3. More studies linking the incidence of PONV with each of the variables studied are required. 